\title{
Welcome climate bloggers
}

A group of just nine climate scientists is trying to change the media coverage of their discipline. Thanks to an ongoing revolution in electronic news, they might just succeed.

$\mathrm{F}$ or those excited about the journalistic potential of the Internet, this September was a seminal month. Much to its embarrassment, the US television network CBS was forced to retract a story about President George W. Bush's service in the armed forces. Crucially, the documents on which CBS based the story were first shown to be a fake not by a hot-shot Washington reporter, but by the authors of a series of blogs — online news diaries penned by unpaid commentators.

Blogs have been around since the late 1990s, but the political potential of this new media format only became truly clear during this year's US presidential race. Bloggers led some of the freshest debates, helped raise money for political parties and, most importantly from a research point of view, corrected mistakes made by other media outlets. At the same time, one more traditional website dedicated to this final purpose - www.factcheck.org - became compulsory reading for journalists who wanted to check the accuracy of claims made by the Bush and Kerry campaigns.

Can researchers make use of this new kind of communication? One group of climate scientists thinks so. The nine researchers ( the United States, three in Europe) launched the RealClimate website - www.realclimate.org - earlier this month. As the News story on page 937 explains, the blog was motivated by the activities of some think-tanks, predominantly from the United States and often run using industry money. Ever since global warming became an issue of media interest, these groups have sought to play down its dangers. RealClimate, say the blog's founders, will provide rapid rebuttals of some of their more egregious statements.

Few would argue with the need to tackle attempts to distort science, but is a blog the best way to do it? The approach certainly has

\section{Wish list 2005}

Nature hereby offers its readers some New Year's resolutions.

W hat would you like to see happen in 2005? We asked a diverse array of researchers - see page 942 for the results. But we decided to indulge ourselves too, and to impudently propose New Year's resolutions for our readers. Our wishes range from optimistic hopes for your even more responsible social behaviour to the more self-interested yearning that our own professional goals (and your enjoyment of Nature) could be made easier to achieve.

Good informatics. Resolve to visit a real library to browse paper journals and books at least once in 2005. And to remind yourself and students that available knowledge on a subject is not restricted to search returns on Google.

Good communication. Resolve to be brave and share your scientific knowledge with the general public, but resist the temptation to say any more than you know. Invite a journalist to lunch to get to know each other's crafts and needs. Offer to speak about your work in front of a school class - even a kindergarten class can be very rewarding and it's important for the young to meet real scientists. And in any its dangers. For example, many issues in climate science, such as the course of temperatures over previous millennia, are hotly debated by researchers. Some would argue that a rapid-rebuttal service, run with minimal peer review, can never hope to combat industry propaganda and properly represent this diversity of views.

Such criticisms are legitimate, but there is no reason that a prompt reply need be unbalanced. The researchers involved will, for example, have to work to ensure that they do not oversell their own opinions when commenting on research issues that divide scientists. Their goal is to provide solid scientific comment to journalists and other interested parties - and there is no reason to doubt that this can be achieved in this fashion.

What will happen if climate researchers do not take this risk? Industry lobbyists, as well as environmental organizations, will be free to distort science to fit their aims. These groups are expert at influencing the media, old and new. Press coverage of climate change is known to overly emphasize the views of the small minority of scientists who dispute the notion of man-made climate change (see Nature 431, 4; 2004). Mainstream climate scientists need to combat this, and RealClimate is, in principle, an excellent way of doing so.

Similar exercises could aid researchers working on nanotechnology and transgenic crops, and other fields with a high media profile. Nature encourages scientists in these disciplines to consider setting up their own blogs, but also to monitor the progress of RealClimate. The site needs to balance speed with objectivity, readability and accuracy. That's no mean feat. Fail, and the blog will be dismissed as no more trustworthy than the myriad lobbying groups already writing on climate. But if the site's founders pull it off, they could change the coverage of climate change for the better. Good luck to them.

presentation, don't pack 50 Powerpoint slides into 10 minutes. Better still, avoid Powerpoint, and engage with people about what you do.

Good citizenship. Spend some of your free time contributing to a public good, such as the Drugs for Neglected Diseases Initiative. Speak out where dogma undermines good scientific advice. And, where you have the chance, resolve to take steps to keep creationism, 'intelligent design' and superstition out of science classes.

Good authorship. Resolve to never submit a paper to Nature until its overall goals and achievements can be understood by, at least, a scientist from another discipline, or even a non-scientist in your family. Always proofread your papers before submitting them to any journal. And avoid phrases such as 'Holy Grail' and 'Rosetta Stone' unless you really mean it.

Good leadership. For those leading research groups, resolve to (continue to) treat your graduate students and postdocs like people, not data slaves, to promote their work actively, and to put their career interests ahead of your own. And ensure that they, like you, have a great New Year. 